\title{
17 SELECTION OF PARTNERS FOR A VIRTUAL ENTERPRISE
}

\author{
L.M. Camarinha-Matos *, T. Cardoso \\ New University of Lisbon, Portugal
}

\begin{abstract}
Electronic procurement of partners is an important functionality during the life cycle of a virtual enterprise. A prototype implementation, featuring selection based on both internal or Internet-based suppliers' directories, is discussed. The generation of call for tenders and support for management of received bids is introduced and directions for contract negotiation and decision support system are discussed.
\end{abstract}

\section{INTRODUCTION}

\section{The need for partners search and selection}

The selection of business partners is a very important and critical activity in the operation of a company. An updated list of suppliers with accurate information is considered an important asset of any industrial company. Similarly, and even in a more acute way, selection of partners is a very important process in the life cycle of a virtual enterprise (VE).

This need comes first in the creation phase of a virtual enterprise. When a new business opportunity is detected, the initiator of the VE - VE broker or VE coordinator - has to look for the most suitable partners for the new consortium. The "core partners" come most naturally from the internal list of previous partners, but other partners are searched for in other sources of information. Furthermore, in a very "volatile" VE, which dynamically changes its composition, in a non-predefined way, partners / suppliers may be unknown a priori. On the other hand, even during the normal operation of a "stabilized" VE, it might be necessary to find suppliers for a particular component or service not offered by other VE members.

Another important opportunity for this activity is in the case of unexpected events. When, during its operation, a VE member has problems in finishing /

\footnotetext{
- Corresponding author address: Universidade Nova de Lisboa, Quinta da Torre, 2825 Monte Caparica, Portugal, tel. +351-1-2948517, fax +351-1-2941253, e-mail: cam@uninova.pt.
} 
fulfilling some contracted business process, one of the possible reactions of the VE coordinator is to look for a substitute supplier.

\section{Electronic procurement}

Recently, a considerable effort has been put in the so-called Electronic Procurement area, especially in the public sector, both in the EU and the USA. The main objectives in this area include the definition of "normalized" procedures for public announcement, reception and management of bids. Most of the efforts, as illustrated by the work of the SIMAP group, in the European Union (SIMAP, 1998), the Association of Proposal Management Professionals in the USA (APMAP, 1996), and the CALS Canada (CALS, 1997), are focused on the attempt to structure the different classes of information to be exchanged and to define standards for this information exchange.

Standardization seems in fact the main obstacle in electronic procurement. For instance, the use of a Universal Product Code is not yet a completely generalized reality. In particular, governments tend to use their own classification schemas.

Another interesting example, following a distinct approach, is given by the NASA Acquisition Internet Service (NAIS, 1999). There, an integrated set of business opportunities can be searched, giving the user the ability to make an integrated search. The USA government plans to develop a "government-wide electronic procurement information system" due to the success of NAIS.

The VE partners search activity shares several similarities with the classic electronic procurement. For instance, both areas include the identification of potential suppliers / partners to be addressed, a desire to achieve normalized specification of requirements and bids, management of directories of potential partners / suppliers, and management of bids. In a more advanced perspective of electronic procurement, both areas can benefit from a computer support for the whole procurement and contract negotiation process (Spinosa et al., 1998).

Another contribution may come from the advances in the Electronic Commerce, namely in terms of the Electronic Catalogs. However, a lack of common standards prevents the easy integration of electronic catalogs from different suppliers and the development of "meta-catalogs". Recent work on applying multi-agent systems and mobile agents to search for potential suppliers and negotiate commercial conditions seems very promising but also suffering from the lack of common models (Rocha, Oliveira, 1999).

But there is also some specificity that makes partners search for a VE a particular case of electronic procurement. First, the objective here is not to simply find a product / system supplier, but to find a partner willing and "deserving" to participate in a joint business process. Although this cooperation might be as simple as the supply of a component / subsystem, it may involve cooperative design, cooperative production planning and supervision, even co-responsibility. Therefore, more than knowing the products' catalog of an enterprise and its commercial conditions, it might be necessary to know the core competencies / business processes and / or technologies of this enterprise as well as its record of reliability and quality. 
Actually, depending on the business area, on the business opportunity or on the business policy, there may exist some particular questions, not significant for other business areas or opportunities, which may be crucial when making the choice between two skilled potential partners.

\section{General approach}

The general approach followed in PRODNET II (Camarinha-Matos et al., 1999) tries to combine different contributions from the related areas mentioned above, but adapting them to the specificity of the VE. Being partners' search a relatively unexplored and rapidly evolving area, it is not possible to make definite proposals about the most adequate approach or a-priori assertions about its feasibility. On the contrary, a step by step experimental approach seems the more appropriate.

It is necessary to understand the tendencies in several related sectors and to make some preliminary proposals that need to be validated before proceeding to the next step. This is particularly valid when the information sources are out of one's control such as the ones provided by independent entities over the Internet. The EPST (Electronic Partners Search Tool) prototype developed in PRODNET II has been validated by the end users of its consortium but it represents only a first step towards general computer-aided partners' search and selection tool.

\section{INFORMATION SOURCES}

Partners search can be based on a number of different information sources, both private and public or independent. The enterprise's private suppliers' list - an important asset of a company - is a data repository that contains information about the companies that have had commercial relationships with this enterprise. This information is usually maintained by the PPC (Production Planning and Control) System and composes an Internal Suppliers Directory (ISD). External sources include directories maintained by industrial associations, commerce chambers, or a new Internet service already available for several countries and that offers WWW interfaces to a database of enterprises served by a local search engine, the External Suppliers Directory (ESD).

The way business run in the past relationships is a key element for choosing one supplier among a set of potential enterprises. Actually, information like delays on delivery time or a good client support reference can make the difference between two potential suppliers. This kind of information is difficult to get about new suppliers. This fact suggests splitting the search into two phases. The first one based on local suppliers' directory and the second one based on external suppliers' lists. The second source is only used if the first fails or if the results are not considered satisfactory. In a few cases some independent entities might possess reference information that help in the qualification of a potential partner, but this information might be expensive or not adequate for the specific search requirements. 
Therefore the assumption in PRODNET II is that when a VE needs to find a new supplier, its coordinator starts the search on its local directory and, if the results are not acceptable or null, then it is necessary to search in external suppliers' lists and contact the potential partners found by this process.

\section{Internal Suppliers Directory}

The existence of a database with historical information related to suppliers which have had some commercial relationships with an enterprise is a convenient resource for a company when it is necessary to look for a product / service. This database and the respective queries are usually stored at the PPC (Production Planning and Control) or ERP (Enterprise Resource Planning) systems, as GEV, the CSIN's PPC used in PRODNET II, does. The exact contents and structure of these databases, although conceptually similar, are different from system to system. Therefore, different members of a VE might have directories of suppliers with a very different structure.

If the PRODNET user has a PPC system, GEV or any other, there is no need to replicate the information stored in the suppliers' database of the PPC system in any other local database. In fact, this possible replication would create new problems as data consistency and coherence. On the other hand, the possibility of a VE node not having a PPC system at all is quite remote. Based on this reality, in PRODNET II it is considered conceptually not adequate to have the same functionality at two different modules of the architecture. Therefore, as a PPC system is integrated with the PRODNET II architecture, the ISD and its search functionality were integrated in the PPC. For the external directories a specific module - the EPST tool - was developed.

\section{Special cluster directories}

More general than a private suppliers' list is a structure that includes a set of enterprises that have some kind of relationship, like being members of the same association, or being members of a cluster formed with the purpose of facilitating the creation of VEs. Such directory is open in the sense that new members may be added, but it is "controlled" in the sense that it is maintained by the coordinator of the association or cluster. This directory is not private of a particular enterprise, as it "belongs" to all members of the association / cluster, but it is not an external independent repository as those ones found in Internet.

One such example can be found in the COSME-VE project (Molina et al., 1998). This project introduces the concept of Virtual Industry Cluster that is an aggregation of companies from diverse industries with well-defined and focused competencies. This directory forms the basis for the creation of dynamic VEs whenever the socalled VE broker finds a suitable new business opportunity. This broker is the entity responsible for searching, in the market, new business opportunities that enable the creation of a VE. In other words, the VE broker is responsible for partners search 
and selection, and VE configuration. It is also likely that the VE broker becomes the VE coordinator once the VE is established.

In the Virtual Industry Cluster directory, an enterprise is described in terms of its core products, core processes, and / or core competencies, which leads to a structure of three sub-clusters. For the product perspective, the directory has a hierarchical organization according to industrial sectors and sub-sectors following the NACE classification. For the other perspectives a private data structure is used. Partners search and selection is based solely on this "controlled" data source. No mechanism for search on External Suppliers Directory is provided.

Another example of a "controlled" cluster of enterprises is proposed by the COWORK project (Martin, 1999). In its directory, the SME Competence Model, each enterprise model includes information on geographic location, application domain, products and processes, services and capabilities. Similarly to the previous example, a new VE is created under the supervision of the main contractor by selecting partners from this directory. An interesting aspect in this approach is the consideration of a negotiation process aimed at reaching the most adequate consortium for the needs of the current task / business opportunity. The cluster of enterprises is focused on product design activities.

A more "open" example of a cluster directory is given by the CORDIS Partners Search service of the European Commission (www.cordis.lu). This directory was created to facilitate the formation of consortia - particular examples of virtual enterprises - for project proposals to be submitted to the European Commission programs. This directory is not organized in terms of enterprises / organizations, but instead in terms of project proposals / ideas. In this way, one enterprise may have several records in this database. Each record includes several information items that can be classified in contact information, enterprise profile (including its competencies), project summary, and requested partners profile. There is an attempt to normalize some parts of this information, namely in terms of the specification of the competencies by using a list of pre-defined sectors / keywords, but it is not obvious that its use is mandatory. Like in the case of many other directories, this one is designed for being used by humans rather by a software program. The maintenance of the database, although moderated, is mainly done by the initiative of the candidate partners. Although more "open" than the previous examples, this is not a general purpose directory of potential partners.

\section{External Suppliers Directories}

Truly external suppliers' directories are new Internet services already existing for several countries. These ESDs, kind of electronic yellow pages, are lists of registered enterprises normally organized by industry sectors or by the class of products they supply. Each ESD has its own data organization and interfacing rules and is maintained by an independent or private organization. There is, in general, an associated search engine prepared to give the user a set of enterprises as a query result, turning the database structure transparent for the user. The query specification is however dependent on the specific ESD. 
Some examples of External Suppliers Directories can be found at:

- http://www.guianet.pt

- http://www.france-companies.com/

- http://www.brazilbiz.com.br/

- http://francexport.com/

- $h t t p: / / n e t i n d e x . i s t . u t l . p t /$

- http://www.tradenet.it/

- http://www.netsearch.co.uk/search.htm

- http://www.paginegialle.it/

- http://yellow.advalvas.be/

- http://www.flix.de/

- http://www.hellas-on-business.gr/home.shtml

- http://www.unc.se/

- http://www.swissdir.ch/

There is also a directory of directories, called PlanetBiz (www.planetbiz.com) that offers a set of registered enterprise directory services organized by country and continent. This directory shows how this new WWW service is spreading around the world.

Unfortunately there are some problems with these services as they appear today:

- There is no uniform information model and organization;

- Although some directories are organized in a hierarchical way by sector, there is no common structure (like UNIDO or NACE industrial sectors classification);

- The search engines and interfacing frameworks are oriented to human users and not to be remotely queried by a program or intelligent software agent;

- The directories are built around "product suppliers" and, therefore, do not give much information on core competencies, core processes, or other "qualitative" information about each enterprise.

The advantage of these information sources is that they are maintained by external specialized entities and, therefore, are likely to be more complete and up to date than private directories. On the other hand, information available in these directories is still limited to contact information, and working areas or classes of products. The CORDIS directory represents a better source to decision making as it includes information such as core competencies, number of employees, turnover, etc.

Considering the number of initiatives on electronic procurement and the developments on Electronic Commerce, some sort of standardization of these directories can be expected in the future. The initiatives on using mobile agents for procurement also suggest that other types of interface, more adequate for a partners search tool, might appear in the future.

\section{SELECTION BASED ON INTERNAL DIRECTORIES}

As mentioned before, PRODNET II supports partners search based on both internal and external suppliers' directories. Search based on ISD is integrated as a functionality of the PPC system. This directory can also be used to support a virtual industry cluster if the VE broker uses the same PPC. 


\section{Directory organization}

The PRODNET ISD is organized as a set of two relational tables: Suppliers and Product/Services. The table of suppliers contains general information on the suppliers such as identification and contact information. The table of products / services relates suppliers with the products / services they can offer. Additional information about the commercial conditions is also included. Examples of the considered attributes are:

- product / service code used by the supplier

- product / service code used by the PPC

- commercial conditions

- minimum and maximum order size

- class of the supplier.

As this directory is integrated with the PPC system, there is a close relationship with the other components of the company's information system. In particular there is a relationship between the ISD and the table of all parts / products handled / processed by the enterprise. This table includes, for each item, information whether the item is manufactured internally, purchased or sub-contracted. In the case of items not manufactured internally, there is also information on the quality procedure / acceptance test level to be applied for each item.

Based on this strong integration it is easier to define the full process of supplier selection with the subsequent ordering / contracting and monitoring phases.

\section{Suppliers classification}

An important aspect in any selection process is the procedure to decide on the qualification of each potential partner. The fitness of a candidate will obviously depend on its capability to offer the required competencies / products and its commercial conditions. But decisions are also based on a number of other factors resulting from the record of performance of the company in the past business relationships.

Information on the constancy of quality (measured by the percentage of rejections / devolution of parts along the time, for instance), delivery times, after sales support, willingness to participate in long term relationships, etc. are important factors in the decision process.

The PRODNET's ISD includes a ranking system that continuously ranks suppliers / partners in a scale of 0 to 100 according to the mentioned factors. The user, according to the policy of the company, configures the relative importance of each factor in the ranking procedure. Finally, suppliers are grouped into three classes - A, B, C - according to their actual rank. For instance: Class A: $80-100$, Class B: 65-79, Class C: $01-64$. 


\section{Selection criteria}

When it is necessary to search and select a partner for a particular business process, both the information on the core competencies and qualification of partners is used. In the current implementation of the CSIN's PPC system, the selection of a partner / supplier from its IDS takes into account the following items:

- Match between the business process requirements and supplier's competencies

- Class of the supplier

- Price and Price/Quality ratio

- Accepted orders size

- Commercial conditions.

Other factors taken into account while the selection is made are the type and the frequency of quality tests and required inspection level. These levels are updated dynamically.

In the COSME-VE approach (Molina et al., 1998) a similar ranking mechanism can be found. When selecting a partner the following general requirements are used:

- Availability

- Good price

- Willingness to participate in long term business relationship

- Constant quality in its products

- Good delivery times.

For each of these variables, COSME-VE defines four classes or levels.

\section{SEARCH BASED ON EXTERNAL DIRECTORIES}

\section{Remote Directory Search}

For partners search in independent external directories available on the Internet, a specific tool (EPST) was developed in PRODNET II (Figure 1). Due to the more experimental nature of this area, consequence of the high heterogeneity of existing ESDs, it makes sense to implement this functionality as a separate module instead of integrating it with the PPC system. Being such directories an emerging area, a considerable level of instability in terms of the ESD structure and interfacing rules is expectable in the near future.

In the current version of the implemented EPST prototype only three particular ESDs are considered:

- GuiaNet - http://www.guianet.pt

- France Companies - http://www.france-companies.com

- Brazil Biz2Biz - http://www.brazilbiz.com.br 


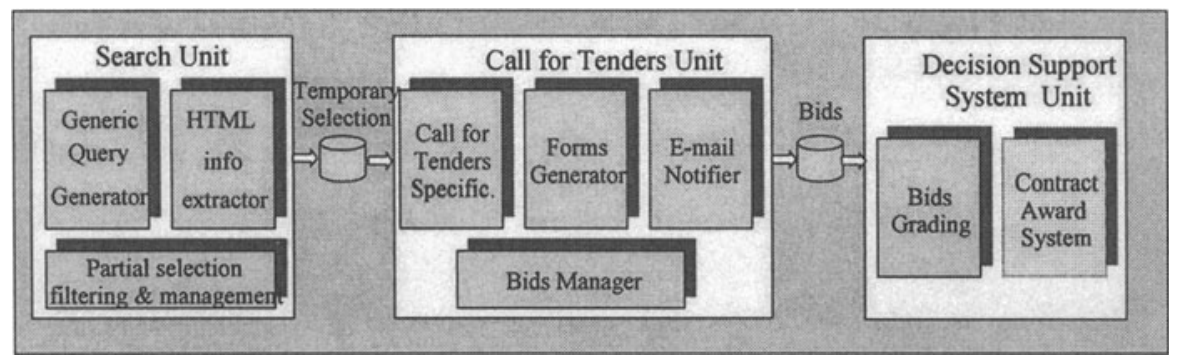

Figure 1 - The EPST architecture

In order to support a general query specification, a meta-directory was created including the relevant attributes of each ESD needed for this tool to run. This metadirectory is mainly composed of the WWW page structure attributes that define how the search query settings are defined by each ESD, as well as how the search results are displayed in the HTML result web page.

According to the initial design goals for this module, the user could dynamically add or remove ESDs from the meta-directory. However, due to the non-standard way ESDs are structured, this option was not feasible for the current implementation.

Figure 1 illustrates the main steps in a multi-ESD search process. After the generic query parameters specification (desired partner profile), the General Query Generator component builds a particular search query string for each ESD (i.e. for its corresponding remote search engine). This string is used to call a function that retrieves the corresponding web page from the Internet.

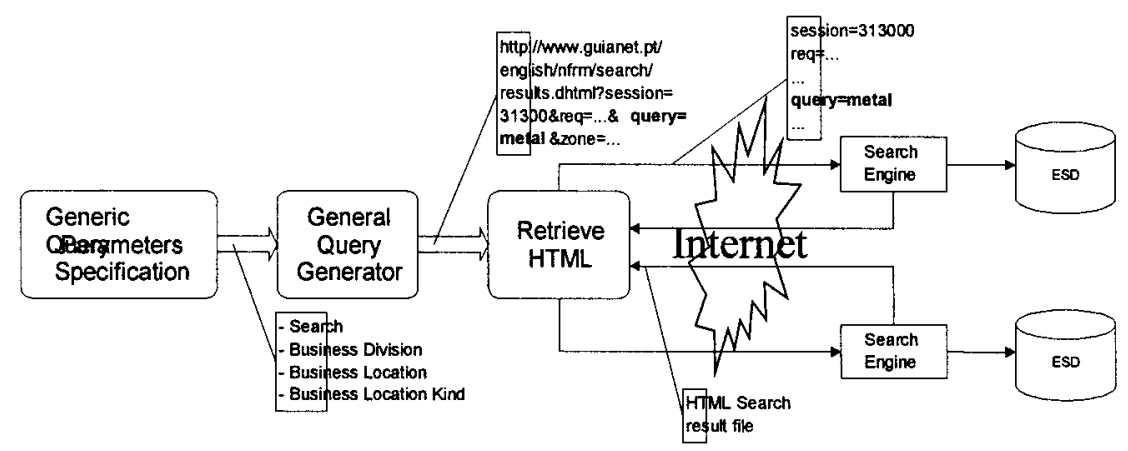

Figure 2 - Information flow diagram in the EPST search process

The partner search query can be submitted in parallel to several ESDs. As current ESDs are designed for human access, their results are returned as generated HTML pages. Figure 2 shows one example.

When the results of these function calls become available, each HTML page is parsed trying to find if the retrieved page contains a list of enterprise groups or the desired enterprises' information. This is necessary in the case an ESD is organized as 
a two-level hierarchy of product / industry sectors (one example is given in Figure 3.b). After this, the page is parsed again twice. The first parsing step extracts the URL of the "next results" link, if one exists. The second step extracts the potential partners' information itself. Because of the non-standard interfacing rules, a specific parser function had to be developed for each ESD.

\begin{tabular}{|c|c|c|}
\hline Type of business & All & 习 \\
\hline Type of international business & All & $\nabla$ \\
\hline \multicolumn{3}{|l|}{ Industry } \\
\hline All & & \\
\hline Target country & All & $\nabla$ \\
\hline Key word search & Gol & \\
\hline metal & & \\
\hline
\end{tabular}

Figure 3.a - France Companies ESD CGI query specification form

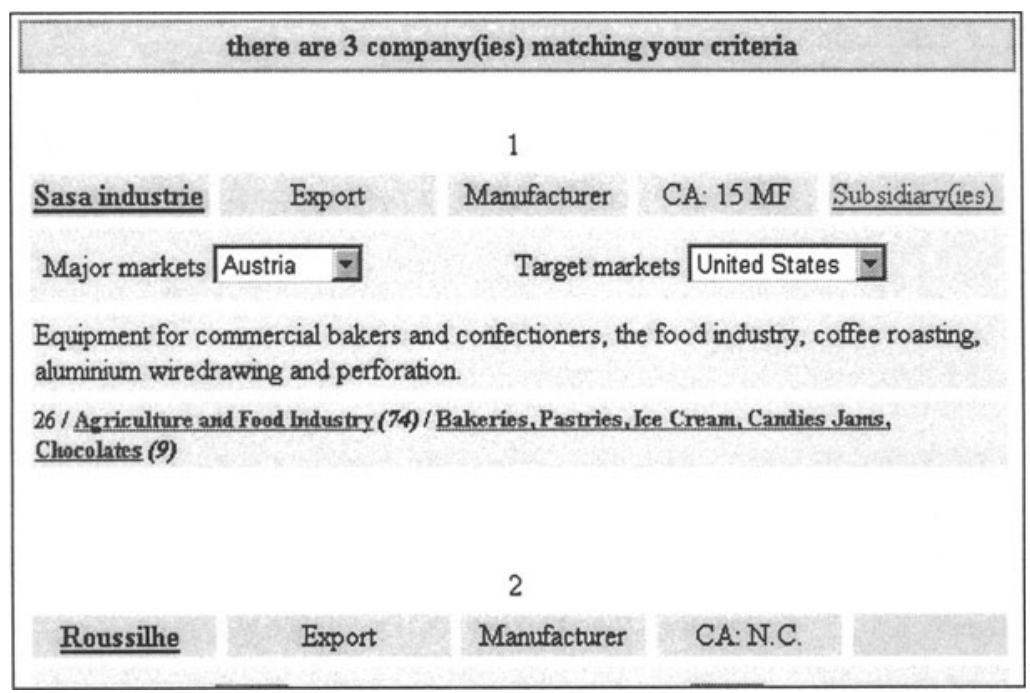

Figure 3.b - Partial example of France Companies ESD search results 


\begin{tabular}{|c|}
\hline Search By: \\
$\nabla$ Search Options: \\
$\nabla$ Internet \\
$\Gamma$ with HomePage \\
$\Gamma$ With Email \\
$\nabla$ Business Location \\
6 Anywhere \\
$C$ County: \\
$C$ District: \\
$C$ Locality: \\
$C$ Zip Code: \\
$\square$ Business Division \\
6 Any \\
$C$ Agenoing \\
$C$ Storing \\
\end{tabular}

Figure 4.a - GuiaNet ESD CGI query specification form.

\begin{tabular}{|c|c|}
\hline $\begin{array}{l}\text { Query: } \\
\text { More than one item was found }\end{array}$ & $\begin{array}{l}\text { metal } \\
\text { Please make a choice: }\end{array}$ \\
\hline Control, Measure And Precisio & $\begin{array}{l}\text { Equipment } \\
\text { - Metal And Ore Detectors }\end{array}$ \\
\hline Road Construction, Road-Sign & $\begin{array}{l}\text { 5. Traffio Lights } \\
\text { - Metal Guards }\end{array}$ \\
\hline Pollution, Waste, Sanitation & - Metal Recycling \\
\hline Building Materials & $\begin{array}{l}\text { - Shapes: Aluminum } \\
\text { (shapes: metal) } \\
\text { - Metalic Nets } \\
\text { (metal-stretched) }\end{array}$ \\
\hline
\end{tabular}

Figure 4.b - Example of insufficient query specification search result

ia

SA

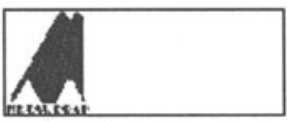

email: metalocar@mail.telepac.pt

Apartado 28

4600 Q atão

Portugal

Tel +351 55.4101000 F ax +35155.424554

more info...

- Fonseca \& Canário, Lda

nower: htto:/hereveguianet.ptifonseca.eanario/

email: dreno.fc@mail.telepac.pt

Casais Comeiras

2050 Aveiras de Cima

Portugal

Tel +351 63.470050 F ax +351 03.470055

more info...

Previcues Next

Figure 4.c - Partial example of GuiaNet final search results 
The obtained information on potential partners is stored in a Temporary Selection table. Filtering this set of potential partners is the next step, performed by the user before the first contact is made by the "Call for Tenders" component. With this Call for Tenders, potential partners are invited to submit a bid regarding their participation in the proposed business opportunity. The final step is performed by the Decision Support System component that sorts the potential suppliers set into the final result list.

Let us now see in more detail how the search process is done:

\section{Search profile specification}

In its current human-oriented interfaces, each ESD has a distinct CGI query specification form at its WWW page. The users are supposed to fulfil the fields in that form that are the inputs for the ESD search engine. Each ESD has its own CGI form structure asking the user different sets of query parameters. Two examples are shown in figures 3.a and 4.a. In order to (partially) avoid this diversity of forms, a simple query form (Fig. 5) was defined, enabling the user to define the query specification parameters only once. The Generic Query Generator makes the necessary translations to build a specific search query string to send to each ESD, using the information stored in the meta-directory. After the query strings are sent to the selected ESDs, the tool waits for the results found by each ESD search engine. Once more, due to the non-standars way ESDs are structured, only the keyword field, from the search settings form, is used in the process.

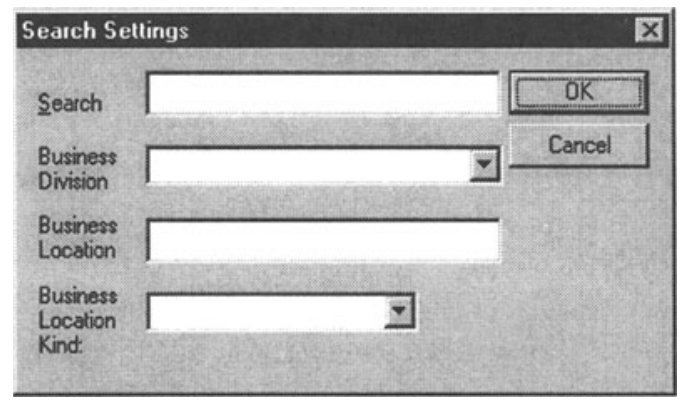

Figure 5-EPST generic query specification form

\section{Information extraction and filtering}

The information items about each enterprise that can be retrieved from these search engines depend on the ESD, as well as on the structure of the returned HTML page.

Based on the analyzed examples, a minimal set of enterprise attributes was defined in the meta-directory, representing the most common information supplied by the current ESDs. These attributes are:

- name of the enterprise

- address, zip code and country

- phone and fax 
- email address and www page URL

- description.

A meta-results-page-format was also defined in the meta-directory schema. This definition includes several attributes used to parse each ESD's results page. The string indicating a "null search result" and the string indicating the existence of "next results pages" are two examples of the information defined in the meta-directory necessary to parse each ESD result file.

Although a meta-directory has been created, a parser had to be developed for each ESDs, as the creation of a generic one is not feasible in the current status of instability of existing directories. This need may disappear in future if the search engines offer interfaces to remote client applications (in addition to the human oriented interfaces), or a HTML standard interface is defined for this kind of services.

\section{Filtering}

This is the second point where the user interacts with the EPST module. A complete set of the potential partners found is shown, structured by fields, in a table format as illustrated by figure 6 .

\begin{tabular}{|c|c|c|c|c|c|c|}
\hline Name & Addiess & Zip Code & Country & Phone & Fax & $\triangle$ \\
\hline tenaulk areeiro & av roma $25-a / d$ & 1000 lisboa & portugal & +3511.7910820 & +3511.7951675 & 5 \\
\hline renault chelas-comseacute,rci... & I dr josteacute; esptiacute... & 1900 lisboa & portugal & +3511.8361400 & +3511.8361480 & \\
\hline auto ideal do nab\&atide;0-aut... & alvito & 2300 tomar & portugal & $+35149-321150$ & $+35149-322640$ & \\
\hline trevauto-com\&eacutexcio, ind... & $t$ arroios $89-a$ & 1150 lisboa & portugal & +3511.3167200 & +351 1-3520096 & \\
\hline mercedes-benz portugal, sa & abrunheira - apartado 1 & 2726 mem m... & portugal & +351 1-9151010 & +3511.9151073 & \\
\hline auto acesstoacute,rios, Ida & I coimbra & 2300 tomar & portugal & $+35149-322937$ & $+35149-322143$ & \\
\hline ecv-electro central vulcanizad... & r constordm; martins carval... & 1400 lisboa & portugal & $+3511-3015361$ & +3511-3017658 & \\
\hline ford lusitana, sa & i rosa ara\&uacuke;jo 2,2tor... & 1250 lisboa & portugal & +3511.3122300 & +3511.3536996 & \\
\hline $\mathrm{m} \times$ car-combeacutexcio e ind... & qttord;: patrim\&oacute,nio L... & 2685 sacav... & portugal & +3511.9415625 & $+3511-9415725$ & \\
\hline parente-auto, Ida & loureira & 2495 santa ... & portugal & $+35144-741282$ & $+35144-741554$ & \\
\hline transmotor, sa & estr circunvalatccedit\&atil. & 4100 porto & portugal & $+3512 \cdot 6194400$ & +3512-6194426 & \\
\hline 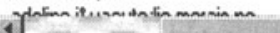 & Claneman & sasplanie & noctound & .251 .4 & 361 $1101 ?$ & \\
\hline$\Delta=$ & & J & 2017) & 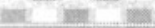 & ant & \\
\hline
\end{tabular}

Figure 6 - Example potential partners retrieved from the GuiaNet EDS

This set can be filtered in various ways according to the user needs. The filter specification consists in the filter kind, filter string, and filter field settings. The filter kind and the filter field are specified through pre-defined values given in two listboxes. There are 4 kinds of filter operators:

- Equal to...

- Starts with...

- Contains...

- Not Null.

These filters can be applied consecutively and / or in parallel, enabling OR's and AND's, respectively (figure 7). The potential partner enterprises set, filtered and without non-satisfactory enterprises, are stored in a Temporary Selection table.

Current directories, although having the advantage of being maintained by independent external entities, offer quite limited information. In particular, qualification information or commercial conditions are normally unavailable. In 
order to support the selection process, additional information has to be collected directly from the enterprises. The next step is then the first contact with the selected enterprises.

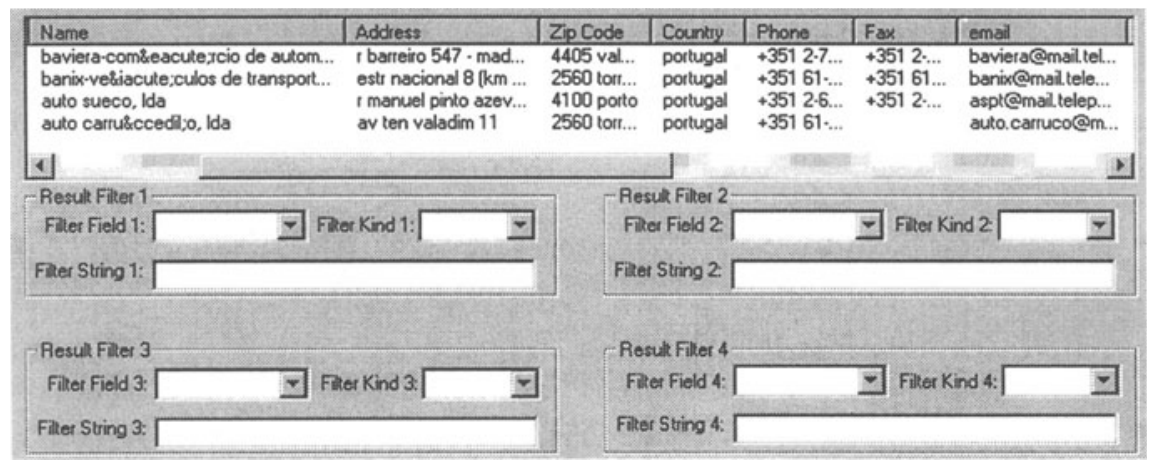

Figure 7 - Example of results from figure 5 filtered with the filter: (Phone Starts with " +351 61" OR "+351 2") AND email Not Null

\section{Enterprise qualification}

As mentioned before, an important element during the selection phase is the qualification information about each enterprise. In terms of the ISDs, enterprises tend to keep an updated record of the performance of their partners. For unknown companies retrieved from an ESD, the available information is rather limited. There is however a business opportunity for independent entities that can collect and organized such qualification information. Some emerging initiatives may point in this direction.

One such initiative is represented by the ENAPS project (ENAPS, 1999). ENAPS is a network of professional agents throughout Europe focused on the improvement of European manufacturing through performance measurement and benchmarking. The network collects standard performance indicators from manufacturing enterprises (mostly Small to Medium-sized Manufacturers or SMEs) throughout Europe and this data is stored in a benchmarking database. The database is then used to analyze a manufacturer's performance in comparison to similar manufacturers in Europe. If successful, at the end of this project, an important new data source could become available. This new directory could then perhaps be used as a source of classified manufacturers, facilitating the selection process.

It is also possible that some of the current search engines associated to ESDs evolve towards intelligent agents performing some (most?) of the brokering functionalities. In this situation, a more complex profile specification for the desired partner will be submitted to this agent that will return a set of suggestions. 


\section{CALL FOR TENDERS}

The information given by the various ESDs is useful to identify potential partners but not enough to classify them. In order to get complementary information for that classification and to start a negotiation process, the Call for Tenders (or Request for Proposals) step can be activated, performing a semi-automated first step in this direction.

\section{Call for tenders generation}

When this function is activated two actions take place (figure 8):

-A HTML/CGI-based form is generated with the set of questions to be answered by interested potential partners;

-An e-mail notification is sent to all enterprises selected in the previous phase, announcing the business opportunity and inviting them to reply via the generated WEB page.

If an enterprise replies before a specified deadline, the answers are used to classify it by a Decision Support System. This classification is then the basis for sorting the list of candidates.

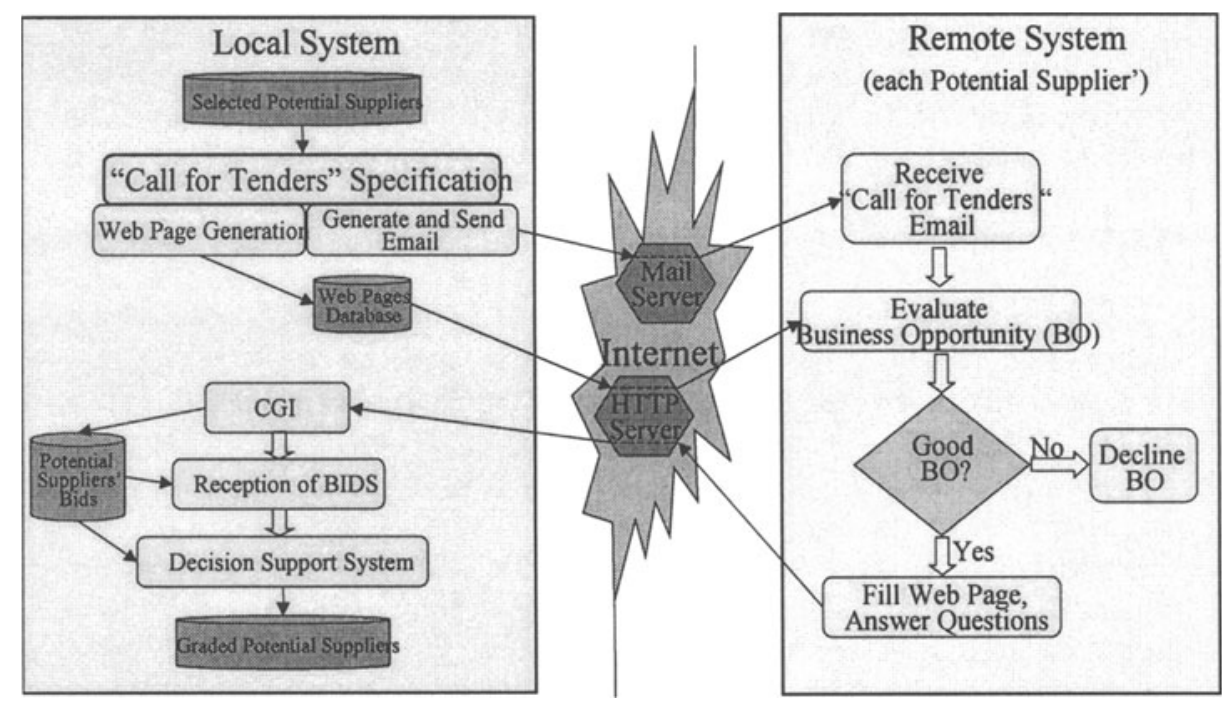

Figure 8 - "Call for tenders" process

The HTML/CGI-based form is composed of several questions intended to gather important information for the decision making (selection) process. In the current version, there are four subsets of information that are requested from candidate partners: 
1. Commercial Conditions information - Before establishing a business partnership, the contractor must know well the commercial conditions offered by the other company. The payment conditions, the delivery time commitments, freight conditions, or the transport insurance, are some examples of important information needed before a partnership can be established.

2. Quality information - Nowadays, quality is an important subject that every company needs to think about. The commitments that a potential partner can make about quality are a very important information in order to define the quality settings of the partnership as a whole. The technical ability, product guaranty, client support / technical assistance / maintenance, or ISO 9000 certification are some examples of possible information to request from a potential partner.

3. Institutional information - The environment surrounding a potential partner is also important. The partners who work with that company, the amount of invoices per year, the client companies, or the number of employees are some examples of information that can make the difference when deciding which enterprise to choose from a set of candidates.

4. Product / Service information - When a standard of the product / service exists, it is possible to ask for a price in advance. The methods used to make the product / service, or the error tolerance guarantees are also important information when choosing a company.

The EPST tool includes a pre-defined set of questions for each of these four sets. When preparing the "Call for Tenders", the user selects the questions he wants to be answered. Furthermore, he can add new questions, other than the pre-defined ones, or remove any question from the given set. When defining a new question, the importance of the answer is also specified enabling the user to customize the Decision Support System.

These four question sets can also be asked in different times, depending on the negotiation policy, splitting the "Call for Tenders" into 2 up to 4 steps, as desired. For instance, if in some particular search, an enterprise needs a partner certified by ISO 9000, there is no need to ask institutional information before knowing if a potential partner has that certification. Therefore, one can split the call for tenders into two different steps, excluding non-certified enterprises from the second contact. The specification of the "Call for Tenders" process consists in the specification of the number of steps that will take place (1 up to 4), which set(s) of questions to be asked in each step, and which questions from each set to be asked.

From the potential partner's point of view, an e-mail will arrive describing a new business opportunity and asking for a bid. If he replies, another e-mail can arrive, if his answers are satisfactory. This process can repeat up to four times.

After the "Call for Tenders" steps are finished, a classification is given by the decision support system to each contacted enterprise.

For new products / parts, technical product data can be exchanged as a STEP file, for instance. Another alternative is to provide limited access to the enterprise's Product Data Management (PDM) system through adequate viewers. One early example in this direction is given by the McDonell electronic bidding system. By 
using this system, business opportunities are sent by e-mail to qualified suppliers who then have secure access via Internet to detailed information about the business, including drawings and manufacturing specifications.

It shall be noted that the exchange of technical detailed data, due to the need of confidentiality, may be started only on later stages of this process or only after a preagreement is established for the supplier to join the virtual enterprise.

\section{Bids management}

As a result of the Call for Tenders, various bids are likely to be received during some time period. On the other hand, a company may issue several Calls for Tenders for different business opportunities. Therefore, it is necessary to have a bids management module. When a response to a business opportunity announcement (bid) arrives, the person who made the announcement receives an e-mail notification. The bids management module (Figure 9) lets the operator inspect the situation regarding received bids, as well as the answers of each potential partner to the sent questions.

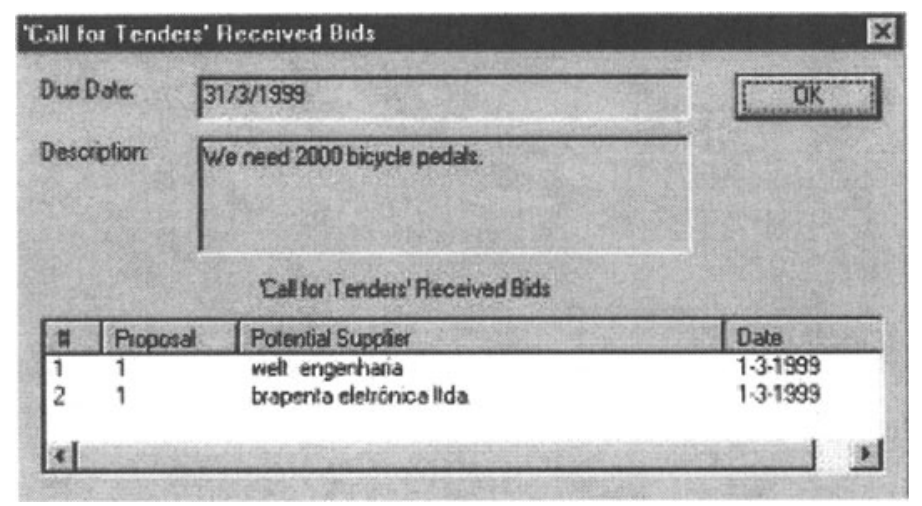

Figure 9 - Bids received for one proposal.

Once the biding phase is finished for a given call, it is possible to evaluate the received proposals.

\section{DECISION SUPPORT SYSTEM}

The decision support system is used to classify the answers given by the potential partners. In the current (limited) implementation, this module considers three types of questions: quantitative questions, multiple-choice questions, and descriptive questions. The first two are automatically evaluated; for the third one the user is asked to help.

The quantitative questions are those that require a numerical answer (Figure 10). 
To evaluate this type of question, the system uses all received answers to this question and sorts the enterprises accordingly (in ascending or descending order).

For each answer a weight is determined by the formula:

(question's weight / number of answers) * sort position.

\section{What is your price condition?}

Figure 10 - Example of a quantitative question.

The user determines the weight of each question.

When multiple choice questions are defined (Figure 11), the user sets which percentage of the question weight corresponds to each possible answer.

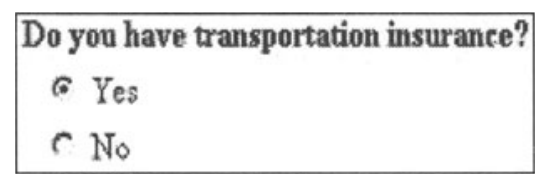

Figure 11 - Example of a multiple-choice question.

In descriptive questions the answer is alphanumerical (Figure 12). It is very difficult to evaluate this kind of questions automatically. Therefore, help from the user is needed. He can better evaluate this kind of answers and give them appropriate weights.

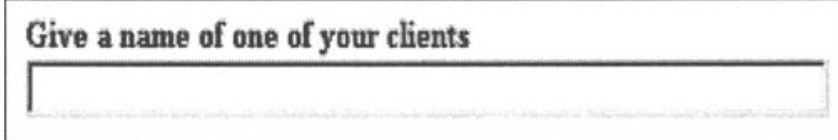

Figure 12 - Example of a descriptive question.

After the proposals' evaluation, a table with the potential partners' grades is shown, sorted by grade (Figure 13). If a contacted enterprise did not answer to the announcement, it will appear with zero as grade.

From this point it is also possible to browse the answers that an enterprise gave to the questionnaire. All answers are shown with the weight obtained for each one.

It is also possible to compare the results graphically. In this way, it is possible to compare the potential partners' answers, one by one, verifying which one has the 
best grade in each answer.

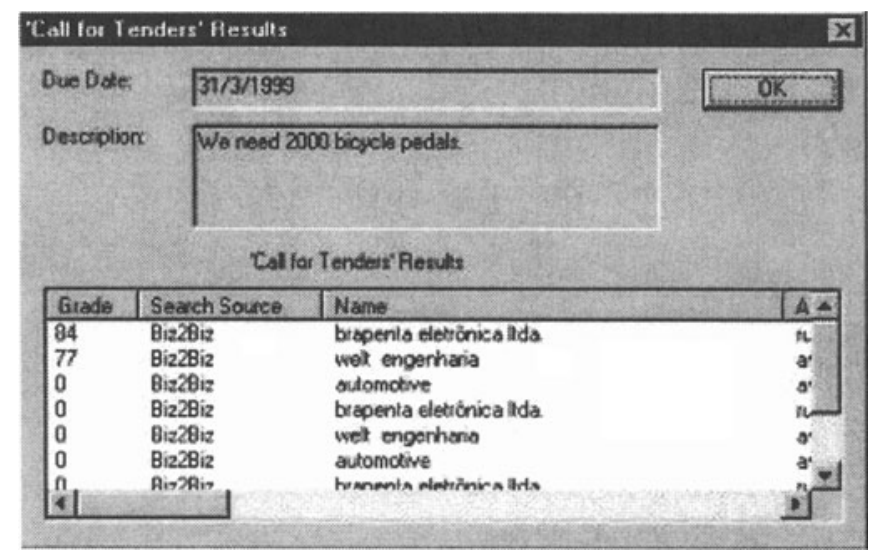

Figure 13 - Call For Tenders Results.

\section{CONCLUSIONS}

Electronic procurement and selection of partners is an important process, both during the creation and the operation of a virtual enterprise.

PRODNET II developed approach and support tools for partners search and selection based on both private and public directories of suppliers.

Due to the lack of standardization of current external suppliers' directories found in the Internet, part of this process has to be customized to each information source. Current developments in the area of electronic business and the use of intelligent brokerage agents suggest that a more "stable" and standardized scenario could be expected in the future, what would allow the development of more general purpose search mechanisms.

Another area requiring further work is the negotiation process before an agreement is reached between the VE and the new partner. In the current implementation this process is quite limited and new experiments on the use of workflow models to guide the negotiation are being done. The management of contracts and the derivation of related coordination clauses, to regulate the behavior of the VE and its members, is another related topic for further research.

\section{Acknowledgements}

This work was funded in part by the European Commission, Esprit programme. The authors also thank the valuable contributions from their partners of the PRODNET II consortium: CSIN (P), HERTEN (BR), MIRALAGO (P), University of Amsterdam (NL), Universidade Federal de Santa Catarina (BR), Universidade Nova de Lisboa (P), Lichen Informatique (F), ProSTEP (Germany), Uninova (P), ESTEC (P). We 
also thank the contribution of the student Nuno Alves in the software implementation.

\section{REFERENCES}

1. APMP - Electronic Procurement Recommendations to improve the process, Association of Proposal Management Professionals, March 1996, http://www.apmp.org/eptf/eptfpapr.pdf.

2. CALS - Reengineering the procurement process, http://cals.debbs.ndhq.dnd.ca/english/reengin2.html

3. CALS - Using brokerage services to develop an "information confederation role of brokers (or "intermediaries") in an information confederation". http://cals.debbs.ndhq.dnd.ca/english/brokerl.htm.

4. Camarinha-Matos, L.M.; Afsarmanesh, H.; Cardoso, T. - Partners search and quality related information exchange in a virtual enterprise, in Proceedings of APMS'99, Kluwer Academic Publishers, Berlin, Germany, Sep 99.

5. Martin, J. - COWORK: IT tools to support Concurrent project development in networks of SMEs, in Proceedings of ICE'99, The Hague, Netherlands, Mar 1999.

6. Molina, A.; Flores, M.; Caballero, D. - "Virtual Enterprises: A Mexican case study". In Intelligent Systems for Manufacturing, L.M. Camarinha-Matos, H. Afsarmanesh, V. Marik, ed.s, Boston: Kluwer Academic Publishers, Aug 1998.

7. ENAPS - European Network for Advanced Performance, 1999, www.enaps.com.

8. NAIS - NASA Acquisition Internet Service - http://procurement.nasa.gov/index.html, http://www.idg.net/new_docids/accounting/general/office/nasa/procurement/electronic/according/e ffective/new_docid_9-123128.html.

9. Rocha, A. P.; Oliveira, E. C. - An electronic market architecture for the formation of virtual enterprises, in Infrastructures for Virtual Enterprises, Edited by L.M. Camarinha-Matos, H. Afsarmanesh, Kluwer Academic Publishers, 1999.

10. SIMAP - Transforming european procurement for the information age, 1998, http://simap.eu.int/EN/pub/src/welcome.htm

11. Spinosa, L.M.; Rabelo, R. J.; Klen, A. P. - High-Level Coordination of Business Processes in a Virtual Enterprise, in Globalization of Manufacturing in the Digital Communications Era of the 21st Century: Innovation, Agility, and the Virtual Enterprise, Edited by Jacucci, G., Olling, G.J., Preiss, K. and Wozny, M., Kluwer Academic Publishers, pp. 725-736. 